terranean, and requesting permission to reproduce certain parts of the book photographically in Egypt for use in the fleet. This, of course, was in the book's earlier days when it was still little known in the Merchant Navy.

\title{
Collision Regulations
}

\author{
from O. W. Neumark
}

Over a decade ago there was some controversy about the selection of an international standard airfield approach lighting system. At a very late stage, the R.A.E. produced a visual simulator of great simplicity on which any administrator could fly approaches using any of the rival systems. His performance could be checked but, what is far more important, he obtained personal and realistic visual experience. If this simulator had been available in 1945 it might have saved many millions spent on the flight evaluations of the rival systems and years of international conferences.

In the present controversy on collision avoidance regulations in the air and at sea, time and wealth could be saved by the creation of a visual and dynamic simulator in which all persons attending symposiums on collision problems could obtain synthetic visual experience of the present day avoidance regulations and of the new conventions proposed by E. S. Calvert and S. H. Hollingdale.

Curiously enough, such a simulator would not be very costly. It would consist of a very large hangar and a number of small electric two-seater cars somewhat similar to those known as 'Dodgems' often seen at Funfairs.

It would be used quite effectively for simulating air traffic as a high percentage of all near-misses occur in the horizontal plane but it would be desirable to gimbal the cars so that they can bank when turning.

Simulation of nocturnal traffic requires only black-out and navigation lights. Day traffic simulation would require painting the floor, walls, ceiling and cars in the same paint scheme to obliterate all detail except for miniature replicas of ships or aircraft on each car. Two-colour filter systems might be even cheaper and more effective.

The essential function of the simulator would be to 'test' the effectiveness of different collision avoidance conventions by direct visual experience without risk.

Multi-body problems, restricted waters, special cases, non-standard navigation and anti-collision lights could all be experienced. Pilot controlled visual collision course beam attacks could be practised.

Such a simulator would be an extremely useful addition to the next symposium on collision problems.

It should be noted that such a 'conference' simulator is in a completely different category to multi-position radar PPI simulators which are essential for training radar navigators and air-traffic controllers.

8* 